\title{
Avaliação de práticas de manejo da mancha-de-Corynespora na cultura do tomate
}

\author{
Rosalee Albuquerque Coelho Netto, Hiroshi Noda, Luiz Alberto Guimarães de Assis \& Francisco Manoares \\ Machado
}

Instituto Nacional de Pesquisas da Amazônia, Coordenação de Sociedade, Ambiente e Saúde, Cx. Postal 2223, 69011-670, Manaus, AM

Autor para correspondência: Rosalee A. Coelho Netto, e-mail: rcoelho@inpa.gov.br

\begin{abstract}
RESUMO
Alternativas de manejo para a mancha-de-Corynespora na cultura do tomate foram avaliadas em dois experimentos em blocos ao acaso em esquema fatorial $(2 \times 3 \times 3)$ com quatro e seis repetições, respectivamente. O primeiro fator foi a cobertura do solo em dois níveis com e sem capim seco picado. O segundo fator foi a pulverização com três níveis: biofertilizante anaeróbico, fungicida e água. O terceiro fator foi o manejo das plantas com três níveis: desbrota, retirada de folhas doentes e sem manejo. A severidade de doença nas folhas e o índice da doença (ID) nas plantas foram avaliados duas vezes por semana e a produção de frutos, no final do ciclo. Os valores das áreas abaixo das curvas de progresso da doença calculadas com valores de severidade e ID e da produção de frutos foram utilizados nas análises estatísticas. A cobertura do solo e a pulverização com biofertilizante não tiveram efeito significativo na intensidade da doença e na produção de frutos. Nas plantas submetidas à desbrota e à remoção de folhas doentes, a severidade da doença foi significativamente menor do que nas plantas sem manejo. Essas práticas provavelmente diminuíram a duração do molhamento foliar nas plantas e a remoção de folhas doentes, também proporcionou diminuição significativa $(\mathrm{P}<0,05)$ da quantidade de conídios de $C$. cassiicola no ar. Estas práticas culturais mostraram-se viáveis para serem utilizadas no manejo da mancha-de-Corynespora em pequenas áreas de produção.

Palavras-chave: Corynespora cassiicola, Solanum lycopersicum, práticas culturais.
\end{abstract}

\begin{abstract}
Evaluation of management practices for corynespora leaf spot of tomato

Corynespora leaf spot management alternatives on tomato crop were evaluated in two experiments laid out in randomized complete blocks in a factorial design $(2 \times 3 \times 3)$, with four and six replications, respectively. The first factor was the soil covering in two levels: soil mulching (dry grass clipping) or bare soil. The second factor was the foliar spraying with three levels: non aerated biofertilizer, fungicide and water. The third factor was the plant management with three levels: selective removal of side shoots, diseased leaf removal or no plant management. The disease severity and disease index (DI) data were assessed twice a week and fruit yield was assessed at the end of the crop cycle. The area under disease progress curves were estimated with severity and DI data and fruit yield data was used to performing statistical analysis. The mulching and the non aerated biofertilizer spraying did not have a significant effect in the disease intensity or in fruit yield. In the plants submitted to selective removal of side shoots and diseased leaf removal, disease severity was significantly lower than in plants not submitted to these treatments. Both plant management practices probably decreased the leaf surface wetness duration in the plant canopy and the diseased leaf removal also significantly reduced $(\mathrm{P}<0,05)$ the number of $C$. cassiicola conidia in the air. These cultural management practices should be used for Corynespora leaf spot management in small production fields.
\end{abstract}

Key words: Corynespora cassiicola, Solanum lycopersicum, management practices.

\section{INTRODUÇÃO}

A mancha-alvo ou mancha-de-Corynespora da cultura do tomate (Solanum lycopersicum L.), causada por Corynespora cassiicola (Berk. \& Curt.) Wei, é considerada a mais séria doença foliar desta cultura em regiões de clima quente e úmido (Jones et al., 1991). Foi relatada na cultura do tomate, pela primeira vez no Brasil, em Manaus, por Alves et al. (1985) e as perdas na região tem sido significativas. Os sintomas da mancha-de-Corynespora se caracterizam principalmente por manchas foliares que se iniciam nas folhas mais velhas e gradualmente aumentam de tamanho e progridem para as partes mais jovens da planta. As lesões resultam em rápido colapso de o tecido foliar que, no entanto, permanece preso à planta. Lesões ocorrem também nos pecíolos, caule e nos frutos. A doença reduz o crescimento vegetativo das plantas, a produção e a qualidade dos frutos tornando-os imprestáveis para a comercialização (Leroy e Lourd, 1989; Pernezny et al., 2002). Os conídios de C. casiicola produzidos em restos culturais são, geralmente, a fonte de inóculo para as primeiras infecções (Kingsland, 1985).

O controle químico da mancha-de-Corynespora na cultura do tomate exige muitas pulverizações e pode não ser 
efetivo nas condições da Amazônia. Além disso, há interesse na diminuição ou eliminação do uso de agrotóxicos na produção familiar de hortaliças na região. Assim, justificase o estudo de alternativas de manejo para essa doença. Práticas culturais como desbrota e cobertura do solo (mulching) podem ser empregadas no manejo de doenças de plantas. Essas práticas modificam o ambiente próximo à planta, interferindo no seu desenvolvimento, na dispersão do patógeno e na duração do período de molhamento foliar (Kumar et al.,2004; Rice et al.,2001; Teasdale e Abdul-Baki. 1997). Também os biofertilizantes, constituídos do resíduo líquido da fermentação do esterco animal ou composto, além de funcionarem como fonte suplementar de nutrientes tem sido usados como uma alternativa para o manejo de doenças e pragas em culturas diversas (Al-Mughrabi et al., 2008; Palmer et al., 2010).

Neste trabalho avaliaram-se alternativas de manejo para a mancha-de-Corynespora na cultura do tomate em plantios submetidos à infecção natural no Amazonas.

\section{MATERIAL E MÉTODOS}

O estudo foi conduzido na estação experimental Alejo von der Pahlen, do Instituto Nacional de Pesquisas da Amazônia (INPA), localizada no Km 14 da rodovia AM 10, em Manaus.

\section{Delineamento experimental}

Dois experimentos foram conduzidos em 2006 e 2007, em blocos casualizados no esquema fatorial ( $2 \mathrm{x}$ $3 \times 3$ ). O primeiro fator foi a cobertura do solo em dois níveis com e sem capim picado. O segundo fator foi a pulverização das plantas com três níveis: biofertilizante anaeróbico, fungicida a base de estrobirulina e água e o terceiro fator foi o manejo das plantas com três níveis: desbrota, retirada de folhas doentes e plantas sem manejo. O experimento 1, em 2006, teve quatro repetições e o experimento 2, em 2007, seis repetições. Os dados de cada variável dos dois experimentos foram analisados em conjunto. As parcelas experimentais constituíram área de $5 \mathrm{~m}^{2}$ com duas fileiras de cinco plantas de tomate da cultivar Yoshimatsu L-3-5, resistente à murcha bacteriana (Ralstonia solanacearum (Smith) Yabuuchi et al.) em espaçamento $0,50 \times 1,00 \mathrm{~m}$, tutorados com estacas de bambu, no sistema de " $\mathrm{v}$ " invertido. Mudas de tomate produzidas em viveiro, em bandejas multicelulares (200 células) de poliestireno expandido, contendo substrato comercial foram transplantadas para o local definitivo aos 38 e 40 dias da semeadura no primeiro e no segundo experimento, respectivamente.

Separando as parcelas experimentais foram plantadas duas fileiras de milho (Zea mays L. cv. BR-106 Pé-de-boi), com espaçamento de $0,30 \mathrm{~m}$ entre plantas. Nas parcelas com cobertura morta depositou-se sobre o solo uma camada de cerca de $3 \mathrm{~cm}$ de altura de capim picado cobrindo toda a área da parcela experimental. A cobertura foi reposta, quando necessário, de forma a manter o solo coberto nas parcelas com este tratamento.

\section{Adubação}

O solo recebeu aplicação de calcário dolomítico na proporção de $200 \mathrm{~g} \mathrm{~m}^{-2}, 30$ dias antes do plantio. $\mathrm{Na}$ adubação de base as plantas receberam $2 \mathrm{~L}$ de composto vegetal, $30 \mathrm{~g}$ de superfosfato triplo, $30 \mathrm{~g}$ de cloreto de potássio, $10 \mathrm{~g}$ de sulfato de amônio e $5 \mathrm{~g}$ de FTE (frited trace elements: B 1,8\%; Cu 0,8\%; Fe 3,0\%; Mn 2\%; Mo $0,1 \%$; Zn 9,0\%), por cova. Foram feitas quatro adubações de cobertura com $10 \mathrm{~g}$ de superfosfato triplo, $10 \mathrm{~g}$ de cloreto de potássio, $5 \mathrm{~g}$ de uréia e $10 \mathrm{~g}$ de sulfato de magnésio.

\section{Pulverizações}

As pulverizações foram semanais utilizandose pulverizador costal manual e os seguintes produtos: 1) biofertilizante produzido pela fermentação anaeróbica, durante 40 dias, de $50 \mathrm{~L}$ de esterco bovino fresco, $10 \mathrm{~L}$ de soro de leite, $1,5 \mathrm{~kg}$ de açúcar e $100 \mathrm{~L}$ de água, diluído em água para $10 \%$ antes da pulverização; 2) fungicida a base de estrobilurina $\left(250 \mathrm{~g} \mathrm{~L}^{-1}\right)$, na dosagem de $0,4 \mathrm{~mL} \mathrm{~L}^{-1} \mathrm{de}$ água; 3) água. Em todos os tratamentos com pulverização acrescentou-se espalhante adesivo a base de nonil fenoxi poli etanol $200 \mathrm{~g} \mathrm{~L}^{-1}$, na concentração de $0,3 \mathrm{~mL} \mathrm{~L}^{-1}$ de água.

\section{Manejo das plantas}

Os níveis do fator manejo das plantas foram: 1) desbrota semanal das hastes laterais; 2) eliminação, duas vezes por semana, das folhas com sintomas da manchade-Corynespora; e 3) plantas mantidas sem podas ou eliminação de folhas (sem manejo). A amarração dos ramos foi realizada duas vezes por semana em todas as plantas e quando necessário as plantas foram irrigadas por aspersão. As capinas foram manuais com enxada e a colheita dos frutos foi feita duas vezes por semana. O manejo das plantas, desbrota e a eliminação de folhas doentes, foi realizado nos dias que antecediam as avaliações de severidade.

\section{Avaliação da intensidade de doença e produtividade das plantas}

As avaliações de intensidade de doença foram realizadas, duas vezes por semana, em cinco plantas selecionadas ao acaso em cada parcela (as mesmas plantas foram avaliadas durante todo o experimento), estimandose o percentual de área doente por planta (severidade) e o índice de doença (ID), calculado pela fórmula:

$$
\mathrm{ID}=\frac{A D}{A T} x 100
$$

(Noda et al., 1997). Onde: ID = Índice de doença; AT = Altura total da planta no momento da avaliação; $\mathrm{AD}=$ Altura máxima atingida pelos sintomas da doença. Com os dados de severidade de doença e de ID foram calculadas as áreas abaixo das curvas de progresso da doença (AACPD), 
de acordo com a fórmula descrita por Campbell e Madden (1990):

$$
\mathrm{AACPD}=\sum_{i}^{n-1}\left(\frac{y_{i}+y_{i+1}}{2}\right)\left(t_{i+1}-t_{i}\right),
$$

onde: $n=$ número de avaliações; $y_{i}$ e $y_{i+1}=$ valores de severidade observados em duas avaliações consecutivas; $\left(t_{i+1}-t_{i}\right)=$ intervalo entre duas avaliações. As avaliações de severidade iniciaram-se aos 40 dias após o transplante, quando os primeiros sintomas da doença foram observados. Os dados de AACPD de severidade e ID e de produção média de frutos por planta foram submetidos à análise de variância pelo teste $\mathrm{F}$ e as médias quando significativas, comparadas pelo teste de Tukey a $5 \%$ de probabilidade. Para a análise estatística foi utilizado o programa SAEG9.1 (Ribeiro Júnior, 2009).

A população de conídios de C. cassiicola no ar foi estimada utilizando-se armadilhas tipo cata-vento preparadas de acordo com a descrição de Reis e Santos (1985). Nessas armadilhas, uma lâmina de vidro para microscopia, coberta com uma fina camada de vaselina constituiu a superfície coletora de conídios. As lâminas foram colocadas nas armadilhas duas vezes por semana e retiradas após 24 horas. Os conídios de $C$. cassiicola aderidos às lâminas foram contados sob microscópio ótico. Vinte e quatro armadilhas foram distribuídas na área experimental, a 1,5 $\mathrm{m}$ de altura. No primeiro ano, as armadilhas foram colocadas em parcelas pulverizadas com água, com e sem cobertura morta e com os três tipos de manejo (desbrota, eliminação de folhas doentes e sem manejo). No segunda ano, as armadilhas foram distribuídas em parcelas sem cobertura morta pulverizadas com fungicida e com água e submetidas aos três tipos de manejo. Os dados do número total de conídios capturados em cada tratamento foram submetidos à análise de variância pelo teste $\mathrm{F}$ após transformação em $\log _{10}(\mathrm{x})$ e as médias, quando significativas foram comparadas pelo teste de Tukey a $5 \%$ de probabilidade.

Durante a frutificação, os tomates produzidos por todas as plantas das parcelas foram colhidos duas vezes por semana e pesados. Os dados de produção média de frutos por planta foram submetidos à análise de variância.

A temperatura e a umidade relativa do ar foram registradas quatro vezes ao dia às 6:00 h, 10:00 h, 14:00 h e 18:00 h utilizando um termo-higrômetro digital (Incoterm, Porto Alegre, RS) e a precipitação pluvial, juntamente com a irrigação por aspersão, foram registradas utilizando um data logger modelo UIZ 3639 (Hioky, Tóquio, Japão), instalado no centro da área experimental a 1,7 $\mathrm{m}$ de altura.

\section{RESULTADOS E DISCUSSÃO}

Os produtos usados na pulverização das plantas e as formas de manejo tiveram efeito significativo nos valores médios de AACPD calculada com dados de severidade e de índice de doença. Para os valores de AACPD com dados de
ID, não se observou diferença significativa entre as plantas submetidas à eliminação de folhas doentes e as sem manejo e estas tiveram significativamente mais doença do que as plantas submetidas à desbrota. Quando a intensidade de doença foi estimada por meio de AACPD com dados de severidade, as plantas submetidas à eliminação de folhas doentes apresentaram valores de AACD significativamente menores do que as plantas submetidas à desbrota e estas, valores significativamente menores do que as plantas sem manejo (Tabela 1). Como o ID considera o desenvolvimento proporcional da doença na planta e como, apesar da eliminação de folhas doentes ser feita de forma cuidadosa, não foi possível eliminar todas as folhas com sintomas no tratamento com eliminação de folhas doentes, qualquer mancha, a uma determinada altura na planta, indicaria a presença da doença mesmo que a severidade na planta fosse baixa. O ID foi menos sensível do que a severidade da doença em detectar diferença na intensidade de doença nas plantas pelo fato de não diferenciar a severidade da doença, mas apenas a incidência de mancha a uma determinada altura na planta. Os diferentes tratamentos não tiveram efeito na produção de frutos que foi em média $1071,8 \mathrm{~g}$ $\operatorname{planta}^{-1}$ (Tabela 1).

Tanto a eliminação de folhas doentes quanto a poda dos ramos laterais reduziram o volume da copa da planta provavelmente contribuindo para melhor aeração e diminuição do período de molhamento foliar. A manchade-Corynespora é favorecida por umidade elevada (Jones e Jones, 1984) e a maior aeração da copa das plantas pode contribuir para a redução da intensidade da doença. No caso da eliminação das folhas doentes pode haver também o efeito da diminuição do inóculo do patógeno. Este efeito foi evidenciado no número de conídios capturados com armadilhas cata-vento nas parcelas com eliminação de folhas doentes que foi significativamente inferior ao número de conídios capturados nas parcelas onde as plantas foram submetidas à desbrota (Tabela 2). Nas plantas submetidas à desbrota os tecidos eliminados eram jovens e ainda não apresentam lesões esporulantes.

Nas plantas pulverizadas com fungicida, os valores de AACPD calculados com dados de severidade da mancha-de-Corynespora e de ID, foram significativamente inferiores aos observadas nas plantas pulverizadas com água e biofertilizante. $\mathrm{O}$ biofertilizante não teve efeito na redução da severidade da doença (Tabela 1). Os resultados do uso de biofertilizantes, extratos de composto ou de esterco para o controle de doenças de plantas são erráticos (Litterick et al., 2004; Al-Dahmani et al., 2003; Elad e Shtienberg, 1994) e estes preparados, isoladamente, não parecem suficientes para evitar perdas em decorrência desta doença. O desempenho de biofertilizantes depende de sua preparação, do tipo de matéria orgânica utilizada, da comunidade microbiana e dos métodos de armazenamento e aplicação. A pressão de inóculo a qual as plantas foram submetidas foi muito alta nos dois anos em que os experimentos foram conduzidos. O manejo da mancha-de-Corynespora nestas situações, 
R.A. Coelho Netto et al.

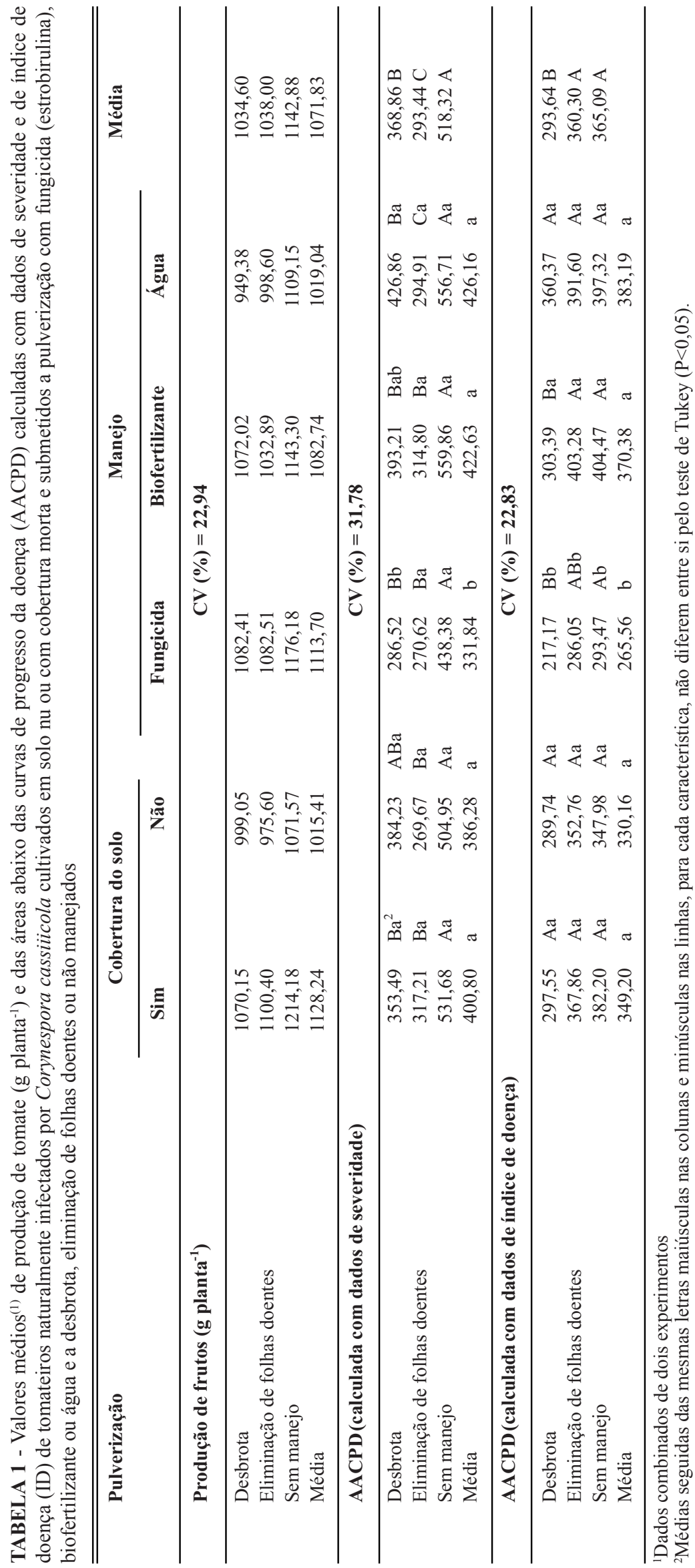


TABELA 2 - Total de conídios de Corynespora cassiicola no ar capturados com armadilhas cata-vento em parcelas cultivadas com tomateiros submetidos a diferentes tipos de manejo

\begin{tabular}{lc}
\hline \hline Tipo de manejo & $\begin{array}{c}\text { Total de conídios } \\
\text { capturados }\end{array}$ \\
\hline Desbrota & $193,25^{1} \mathrm{a}^{2}$ \\
Sem manejo & $188,88 \quad \mathrm{ab}$ \\
Eliminação de folhas com & $140,88 \quad \mathrm{~b}$ \\
sintomas & \\
\hline
\end{tabular}

${ }^{1}$ Para as análises estatísticas os dados foram transformados em $\log _{10}(\mathrm{x})$;

${ }^{2} \mathrm{Os}$ valores nas colunas seguidos das mesmas letras não diferem significativamente pelo teste de Tukey $(\mathrm{P}<0,05)$.

mesmo com o uso de fungicidas eficientes é difícil (Pernezny et al., 1996). Fungicidas a base de estrobirulina, em rotação com fungicida de amplo espectro já foram usados com sucesso no controle da mancha-de-Corynespora na cultura do tomate, reduzindo a severidade da doença em até quatro vezes (Pernezny et al., 2002; 2005). No entanto, para mais de 20 patógenos, como Alternaria solani Sorauer, Didymella bryoniae (Auersw) Rehn, Mycosphaerella fijiensis Morelet, Pyricularia grisea Sacc. e também para C. cassiicola, já foi constatada resistência de campo, à estrobirulinas (Ishii, 2006).

Avaliando-se a intensidade da doença por meio do ID, a ocorrência de uma lesão em uma folha na porção mais alta da planta, mesmo em uma planta com baixa severidade de doença, leva a uma superestimação da quantidade de doença. Assim, podem ocorrer plantas com valores iguais de ID e com grandes diferenças nos valores de severidade. Mesmo sendo a avaliação de severidade subjetiva, sem um parâmetro para comparação dos valores estimados com a severidade real, o método permitiu discriminar melhor os efeitos dos tratamentos avaliados.

A cobertura do solo poder atuar diminuindo a dispersão de patógenos que sobrevivem no solo ou em restos de cultura (Madden e Ellis, 1990; Abdul-Baki et al., 1996; Ntahimpera et al., 1998). Nos experimentos, porém, não se observou atraso do início da epidemia nas parcelas com cobertura morta. Apesar de conídios produzidos em restos culturais serem uma das principais fontes de inóculo primário para a mancha-de-Corynespora na cultura do tomate (Kingsland, 1985), não se pode afirmar que esses conídios foram a fonte de inóculo primário para as plantas do experimento já que a população de conídios nos restos culturais não foi quantificada.

A infecção por C. cassiicola ocorre com temperaturas variando de 16 a $32^{\circ} \mathrm{C}$, principalmente nas primeiras horas da manhã (Jones e Jones 1984). Durante o período de condução dos experimentos, as condições de temperatura e umidade relativa do ar estiveram sempre na faixa ótima para a infecção. A média de temperatura às $6: 00 \mathrm{~h}$ foi $25,6^{\circ} \mathrm{C}$ e no horário mais quente do dia, às 14:00 h de $30,9^{\circ} \mathrm{C}$. Essas condições ótimas para a infecção e a esporulação do fungo podem ter mascarado o efeito dos tratamentos devido ao alto potencial de inóculo na área experimental.

Na Amazônia, a condição altamente favorável à C. cassiicola, a presença de diversas espécies hospedeiras, a possibilidade de sobrevivência do fungo como saprófita, sua abundante esporulação e a variabilidade da sua população natural, reforçam a necessidade de se buscarem alternativas de manejo para essa doença na cultura do tomate. $\mathrm{O}$ nível de controle obtido com práticas culturais pode ser, muitas vezes, considerado insuficiente para a agricultura convencional porém, na produção orgânica, com limitadas estratégias de controle, opções que permitem a diminuição da intensidade da doença podem ser importantes no contexto das estratégias de manejo. Assim, práticas de manejo como a eliminação de folhas doentes, podem ser alternativas no manejo da mancha-de-Corynespora em cultivos familiares no Amazonas.

\section{AGRADECIMENTOS}

Os autores agradecem ao Conselho Nacional de Desenvolvimento Científico e Tecnológico - CNPq pelo suporte financeiro para execução dessa pesquisa e a Miguel Ângelo Branco Camargo e Francy Mary Galúcio Sousa pelo auxílio nos trabalhos de campo e laboratório.

\section{REFERÊNCIAS BIBLIOGRÁFICAS}

Abdul-Baki AA, Stommel JR, Watada AE, Teasdale JR, Morse RD (1996) Hairy vetch mulch favorably impacts yield of processing tomatoes. HortScience 31:338- 340.

Al-Dahmani JH, Abbasi PA, Miller SA, Hoitink HAJ (2003) Suppression of bacterial spot of tomato with foliar sprays of compost extracts under greenhouse and field conditions. Plant Disease 87: 913-919.

Al-Mughrabi KI, Bertheleme C, Livingston T, Burgoyne A, Poirier R, Vikram A (2008) Aerobic compost tea, compost and a combination of both reduce the severity of common scab (Streptomyces scabiei) on potato tubers. Journal of Plant Sciences $3: 168-175$

Alves MLB, Lourd M, Noda H (1985) Ocorrência de Corynespora cassiicola em caráter epidêmico em tomatais de Manaus. Fitopatologia Brasileira 10:229. (Resumo)

Campbell CL, Madden LV (1990) Introduction to plant disease epidemiology. New York EUA. John Wiley \& Sons.

Elad Y, Shtienberg D (1994) Effect of compost water extracts on grey mould (Botrytis cinerea). Crop Protection 13:109-114.

Ishii H (2006) Impact of fungicide resistance in plant pathogens on crop disease control and agricultural environment. Japan Agricultural Research Quarterly 40:205-211.

Jones JB, Stall RE, Zitter TA (Eds.) (1991) Compendium of Tomato Diseases. St. Paul EUA. APS Press.

Jones JP, Jones JB (1984) Target spot of tomato: Epidemiology and control. Proceedings of the Florida State Horticultural Society 97:216-218. 
Kingsland GC (1985) Pathogenicity and epidemiology of Corynespora cassiicola in the republic of the Seychelles. Acta Horticulturae 53:229-230.

Kumar V, Mills DJ, Anderson JD, Mattoo AK (2004) Delayed senescence and disease tolerance of tomato plants cultivated in cover crop mulch correlates with accumulation of specific gene products. Acta Horticulturae 638:497-502.

Leroy M, Lourd M (1989) Doença foliar do tomateiro causada por Corynespora cassiicola em Manaus. Fitopatologia Brasileira 14:32-36.

Litterick AM, Harrier L, Wallace P, Watson CA, Wood M (2004) The role of uncomposted materials, composts, manures, and compost extracts in reducing pest and disease incidence and severity in sustainable temperate agricultural and horticultural crop production - A review. Critical Reviews in Plant Science 23:453-479.

Madden LV, Ellis MA (1990) Effect of ground cover on splash dispersal of Phytophthora cactorum from strawberry fruits. Journal of Phytopathology 129:170-174.

Noda H., Paiva WO, Silva Filho DF, Machado, FM (1997) Melhoramento de hortaliças convencionais para cultivo no trópico úmido brasileiro. In: Noda H, Souza LAG, Fonseca OJM (Eds.) Duas décadas de contribuições do INPA à pesquisa agronômica no Trópico Úmido. Manaus AM. INPA. p. 59-87.

Ntahimpera N., Ellis MA, Wilson LL, Madden LV (1998) Effects of a cover crop on splash dispersal of Colletotrichum acutatum conidia. Phytopathology 88:536- 43.

Palmer AK, Evans KJ, Metcalf DA (2010) Characters of aerated compost tea from immature compost that limit colonization of bean leaflets by Botrytis cinerea. Journal of Applied Microbiology 109:1619-1631.

Pernezny K, Stoffella P, Collins J, Carroll A, Beaney A (2002) Control of target spot of tomato with fungicides, systemic acquired resistance activators, and a biocontrol agent. Plant Protection Science 38:81-88.

Pernezny K, Stoffella P, Havranek N, Sanchez J; Beany A (2005) Bam! Kicking control of target spot up a notch. Acta Horticulturae, 695:175-180.

Pernezny K, Datnoff LE, Mueller T, Collins J (1996) Losses in fresh-market tomato production in Florida due to target spot and bacterial spot and the benefits of protectant fungicides. Plant Disease 80:559-563.

Reis EM, Santos HP (1985) População de Helminthosporium sativum no ar quantificado através de uma armadilha tipo catavento. Fitopatologia Brasileira 10:515-519.

Ribeiro Júnior, J.I. 2009. Guia prático para utilização do SAEG. Viçosa MG. Folha.

Rice PJ, McConnell LL, Heighton LP, Sadeghi AM, Isensee AR, Teasdale JR, Abdul-Baki AA., Harman-Fetcho JA, Hapeman CJ (2001) Runoff loss of pesticides and soil: A comparison between vegetative mulch and plastic mulch in vegetable production systems. Journal of Environmental Quality 30:18081821.

Teasdale JR, Abdul-Baki AA (1997) Growth analysis of tomatoes in black polyethylene and hairy vetch production systems. HortScience 32:659-663.

TPP 275 - Recebido 20 Março 2011 - Aceito 2 Maio 2012

Editor de Seção: Nilceu R.X. Nazareno 